\title{
PARA UMA HISTORIOGRAFIA DA HISTORIOGRAFIA PORTUGUESA DO JORNALISMO: os livros pioneiros ${ }^{1}$
}

\author{
For a historiography of the Portuguese historiography of journalism: \\ the early books
}

\author{
Jorge Pedro Sousa
}

Doutor e Pós-Doutor pela Universidade de Santiago de Compostela, livre-docente (agregado) pela Universidade de Trás-os-Montes e Alto-Douro, professor de Jornalismo na Universidade Fernando Pessoa. Porto, Portugal, e-mail: jorgepedrosousa@hotmail.com

\begin{abstract}
Resumo
Este trabalho, baseado em pesquisa bibliográfica, apresenta, sinteticamente, as obras pioneiras dedicadas à história do jornalismo publicadas em Portugal por autores portugueses até à revolução de 25 de abril de 1974. Procurou-se resgatar obras obscurecidas pela história, dando conta, simultaneamente, dos assuntos nelas abordados e das suas eventuais peculiaridades discursivas. Mostra-se que as histórias do jornalismo em Portugal, que começarama a ser publicadas, como noutros países, no século XIX e princípios do século XX, dividiram-se por várias categorias, nomeadamente: histórias biográficas (26\%); histórias do jornalismo regional e local (18\%); histórias do jornalismo português $(15 \%)$; e histórias do jornalismo colonial $(13 \%)$. Considera-se que, entre as obras mais relevantes, duas delas merecem particular atenção: Elementos para a História da Imprensa Periódica Portuguesa, de Alfredo da Cunha (1941a), uma obra notável pelo seu pioneirismo e que proporcionou abundantes dados sobre a história do jornalismo português até 1820, muitas vezes referidos, sem menção à origem, em obras posteriores; e História da Imprensa Periódica Portuguesa, de José Manuel Tengarrinha (1965, reeditada em 1989), obra que ainda hoje é a mais representativa da historiografia portuguesa sobre jornalismo, sendo uma das que documentam, em Portugal, o abandono das teses da historiografia positivista nascidas no século XIX em favor de uma concepção mais complexa e multidimensional da história.
\end{abstract}

Palavras-chave: História do jornalismo. Portugal. Historiografia.

\begin{abstract}
This work, based on bibliographical research, presents, in summary, the pioneering works devoted to the history of journalism published in Portugal by Portuguese writers until the Revolution of April $25^{\text {th }} 1974$. We have tried to
\end{abstract}

1 Esta pesquisa foi apoiada pela Fundação para a Ciência e a Tecnologia, projecto PTDC/CCI-JOR/100266/2008. 
rescue works obscured by history, presenting both the subjects they cover and their possible discourse peculiarities. It is shown that the histories of journalism in Portugal started to be publish, like in other countries, during the $19^{\text {th }}$ century and in the beginning of the $20^{\text {th }}$ century. It is also revealed that Portuguese books about the history of journalism can be divided in several categories, including: biographies (26\%); history of local journalism (18\%); history of Portuguese journalism (15\%); and history of colonial journalism (13\%). Among those books, two of them deserve special attention: Elementos para a História da Imprensa Periódica Portuguesa, written by Alfredo da Cunha (1941a), a work remarkable for its pioneering spirit and that come up with factual data widely quoted, sometimes hiding the origin, in later works; and História da Imprensa Periódica Portuguesa, written by Jose Manuel Tengarrinha (1965, reprinted in 1989). This work still is the most important representative of the Portuguese historiography of journalism and it documents, in Portugal, the abandoning of the $19^{\text {th }}$ century thesis of positivist historiography, in favour of a more complex and multidimensional historiography.

Keywords: History of journalism. Portugal. Historiography.

\section{INTRODUÇÃO}

Jornalismo e história são aparentados. O jornalismo é uma memória discursiva dos acontecimentos e problemáticas a que, em cada contexto particular, uma sociedade deu importância. Por isso, os historiadores cedo compreenderam que os jornais e, mais tarde, outros meios de comunicação jornalística, são também documentos históricos, fontes para a edificação da história, capazes de "mostrar a realidade" ou, pelo menos, uma realidade, com elevada capacidade de indicidade ou até de iconicidade.

No século XIX, alguns historiadores se deram conta de que os jornais, para além de serem relevantes documentos históricos, são, também, dispositivos sociais de relevo. Os historiadores oitocentistas não puderam, de fato, deixar de notar, no seu tempo, o impacto que os jornais tinham, particularmente a partir do momento em que os periódicos populares começaram a tirar milhares ou mesmo milhões de exemplares. Surgiram, assim, as primeiras histórias do jornalismo. Pode dizer-se, em concomitância, que a história do jornalismo, em particular a história da imprensa, é uma das disciplinas fundadoras dos Estudos Jornalísticos ou, se quisermos, do Jornalismo como campo científico, que se estrutura no século XIX, a partir da emergência das ciências sociais e das primeiras teorias que olharam para a imprensa como instituição social.

A história das Actas Diurnas, resgatada por Le Clerc (1838), ou a história da gênese do jornalismo alemão, de Prutz (1971), dada à estampa em 1845, são apenas dois dos exemplos a que poderíamos aludir para defender a tese do contributo fundacional da História para a definição do campo dos Estudos Jornalísticos. Mas não são os únicos. No Reino Unido, Alexander Andrews (1859) publicou uma monumental história do jornalismo britânico, a que se seguiram estudos similares de Bourne (1887), Morison (1932), Stutterheim (1934) e outros. Por seu turno, Ernst Bernheim (1908), da Universidade de Leipzig, fez um esboço histórico do jornalismo antigo. Eugène Hatin (1859-1864) escreveu uma monumental obra em oito volumes sobre a história política e literária da imprensa francesa, a que se seguiu, em 1866 (HATIN, 1866), um ensaio bibliográfico e estatístico sobre o aparecimento e desenvolvimento da imprensa periódica na Europa e nas Américas. O alemão Ludwig Salomon (1900-1906) elaborou, por sua vez, uma história da imprensa alemã, com especial ênfase para o período até 1850, na qual recupera, em particular, os contributos dos primeiros diários alemães do século XVII para o desenvolvimento do jornalismo. Del Arco y Muñoz (1914) publicou um estudo históricobibliográfico sobre a imprensa periódica espanhola durante a Guerra da Independência, a que se seguiu, também na Espanha, uma história do jornalismo, dada à estampa por Edmundo González-Blanco.

Nos Estados Unidos, o interesse pela história do jornalismo também foi despoletado no século XIX, com o trabalho de Hudson (1873), prosseguindo, no século XX, com os de Lee (1917), Bleyers (1927) e Mott (1962). A grande novidade trazida pelas obras desses autores norte-americanos foi a atenção que devotaram à institucionalização da profissão de jornalista. Uma teórica norte-americana, Ishbel Ross (1936), orientou a historiografia jornalística para as questões de gênero, ao escrever sobre as Ladies of the 
Press. Em 1944, Kobre lançou, também nos Estados Unidos, uma história da imprensa colonial, na qual encara essa última como instituição social. O estudo de Kobre (1944) contextualiza, assim, o aparecimento e evolução dos jornais em consonância com a própria evolução da sociedade, na mesma perspectiva que Park (1923) tinha apontado, no seu trabalho sobre a história natural do jornal. O trabalho de Kobre chamou também a atenção para o facto de o historiador do jornalismo se deparar com um objecto vasto e complexo, que pode analisar-se desde diferentes perspectivas, desde a história clássica à sociológica, econômica ou tecnológica, entre outras. Mais, o jornalismo não é um objecto de estudo isolado, está relacionado com outros objectos e práticas sociais, institucionais e culturais, entre as quais as práticas políticas, as económicas e as empresariais.

Num outro tom, Ernst Bernheim (1908) publicou, em Leipzig, o livro Lehrbuch der Historischen Methodik und der Geschichtphilosophie, no qual ele relembra os contributos dos autores alemães do século XVII para a teorização do jornalismo. Aparentemente, terá sido o primeiro esforço para historiografar não apenas o jornalismo mas também os estudos jornalísticos.

Outro tipo de livro coadjutor do campo dos estudos jornalísticos é constituído pelas obras hemerográficas (inventários de livros e artigos sobre jornalismo) e biobibliográficas (biografias e bibliografias de jornalistas, memórias de jornalistas etc.). As últimas décadas do século XIX e as primeiras do século XX são bastante ricas nesse tipo de estudo, de que são exemplos os trabalhos histórico-hemerográficos de Gracias (1880), Leal (1898), Noronha (1857), centrado na tipografia; e Pereira $(1895,1897)$.

Ora, apesar da abundância de histórias do jornalismo, não deixa de ser curioso que alguns dos mais antigos contributos para a construção de conhecimento histórico sobre o jornalismo tenham sido ofuscados pelo tempo. Pouco conhecidos, pouco citados, porvezes parece que algum do conhecimento posterior divulgado pelas histórias do jornalismo mais recentes nada deveu aos precursores que desbravaram o campo e reuniram muitos dos dados que hoje são amplamente referidos como fatos pelos historiadores mais recentes do jornalismo. Impõe-se, portanto, resgatar as obras pioneiras sobre história do jornalismo, fazer uma historiografia da própria construção de conbecimento histórico sobre o jornalismo, de maneira a ser possível avaliar quanto do que se sabe hoje em dia sobre esta nobre, útil, importante e influente atividade estratégica de comunicação em sociedade se deveu ao trabalho dos historiadores que primeiro se debruçaram sobre ela. Este trabalho procura contribuir para se alcançar esse objectivo.

\section{AS HISTÓRIAS DO JORNALISMO EM PORTUGUÊS E POR PORTUGUESES ATÉ 25 DE ABRIL DE 1974}

O interesse de autores portugueses pela história do jornalismo, em particular pela história da imprensa, data do século XIX. O primeiro indício que se pode recolher sobre esse interesse, tanto quanto se pôde apurar, data de 1857. Trata-se de um pequeno livro, intitulado Ensaios Sobre a História da Imprensa, escrito por Tito de Noronha, sobre a introdução e evolução da tipografia em Portugal. Nele, colateralmente, são apresentados dados sobre as primeiras relações e folhas noticiosas, bem como sobre os primeiros jornais portugueses (onde foram impressos, quem os imprimiu etc.). José António Ismael Gracias (1880) desenvolveu o mesmo tipo de pesquisa, mas circunscrevendo-a à Índia Portuguesa, concretamente a Goa.

Foi a partir das duas últimas décadas do século XIX que se tornou constante o interesse pela história do jornalismo em Portugal. Eduardo Coelho (1881) evocou o nascimento e desenvolvimento do jornalismo em Portugal numa comunicação apresentada ao Congresso Literário Internacional de Lisboa, tendo feito o mesmo em 1898 (COELHO, 1898), por ocasião da celebração, também na capital do país, do V Congresso Internacional da Imprensa, evento em que foi acompanhado, no tratamento do mesmo tema, por Alfredo da Cunha (1898), que 43 anos mais tarde publicaria uma importante história do jornalismo português até 1821 (CUNHA, 1941a), na qual autores posteriores recolheram abundantes dados.

A partir do fim do século XIX, há várias orientações no tratamento da história do jornalismo. Alguns autores publicam obras sobre a história do jornalismo em geral (por exemplo: BESSA, 1904; LACERDA, 1904; CUNHA, 1930, 1939, 1941 a, b, 1942; MARTINS, 1942; PEREIRA, 1895, 1897; SALGADO, 1945; TENGARRINHA, 1965; ROSADO, 1966); outros debruçam-se sobre a imprensa e o jornalismo nas colônias ou em 
regiões e cidades do país (por exemplo: ARAGÃO, 1900; CUNHA, 1929; BASTO, 1940; BRANCO, 1938; BRITO ARANHA, 1885; CARVALHO, 1931; CODAM, 1973; COSTA, 1963; CUNHA, 1893; DIAS; EÇA, 1957; FERNANDES, [19-?]; FREITAS, 1908; GALRÃO, 1937; GAMA, 1956; GONÇALVES, 1964, 1965，1966，1966/1967; GRAVE, 1929;JESUS, 1955; LAPA, 1956; MARTA, 1921; MONTE, 1955; NUNES, 1962; OLIVEIRA, 1958; OLIVEIRA, 1969; SILVA LEAL, 1898; TEIXEIRA, 1965). Gonçalves (1972) merece destaque por abordar a história do jornalismo português desde o ponto de vista dos condicionamentos legais ao seu desenvolvimento. Outros ainda se restringem à história do jornalismo especializado, nomeadamente nas áreas da medicina (PINA, 1945; SILVA, 1974), do cinema (COSTA, 1954) e da imprensa operária (OLIVEIRA, 1973). Esse último trabalho (Imprensa operária no Portugal oitocentista: 1825-1905, de César Oliveira) é particularmente interessante porque aborda temas sensíveis, como a imprensa socialista e anarquista e o respectivo discurso, numa época em que o regime ditatorial e corporativista censurava tudo o que pudesse soar a subversão. Também é relevante por cruzar sociologia política com a história, como advogavam as correntes que reagiram contra a história positivista de Oitocentos.

No âmbito da produção historiográfica portuguesa sobre jornalismo encontram-se, igualmente, obras sobre a história de determinados jornais (por exemplo: BAPTISTA, 1966; CARQUEJA, 1924, 1934; CERQUEIRA, 1952; CUNHA, 1914; FREIRE, 1939; MACIEL, 1958; MORAIS, 1941; MORAIS, T., 1941; PACHECO, 1964; TEIXEIRA, 1940), com especial destaque para o Diário de notícias e $O$ comércio do porto. A obra de Jacinto Baptista (1966) é singularmente interessante por se tratar de uma profunda análise do discurso do número do jornal republicano $O$ mundo, de 5 de outubro de 1910, data em que a República foi proclamada em Portugal. Aliás, é uma das primeiras análises do discurso realizadas em Portugal, uma das primeiras histórias a tentar integrar um problema histórico no seu contexto, ultrapassando os limites da história clássica positiva.

Descobriram-se, ainda, catálogos que descrevem jornais, como o de João Pereira da Silva (1892) e o de José Luciano Castro (1897), preciosos auxiliares para o estabelecimento de uma história do jornalismo em Portugal, e até um livro sobre a história da imprensa brasileira editado em Portugal por um português (BESSA, 1929).

A história das organizações jornalísticas e das personagens que nelas intervieram não foi esquecida pelos autores portugueses, sendo abordada por Luís Gomes (1925), Alfredo da Cunha (1941b) e por Boavida Portugal (1959), nesse último caso restrita à Casa da Imprensa.

Finalmente, um derradeiro grupo de livros historiográficos é constituído pelas biografias de jornalistas e "escritores de jornais", normalmente já falecidos. Essas obras tendem a enaltecer, frequentemente em tom apologético, os biografados, mas são úteis para resgatar os contributos de determinados vultos - autores - ao jornalismo português. São, entre outros, exemplos desse tipo de obras a de Morais (1941) sobre Lourenço de Anvers, impressor do primeiro e outros números da Gazeta "da Restauração"; a de Anselmo (1882), a de Veloso (1910-1911) e a de vários autores (PINTO et al., 1882) sobre o jornalista e político António Rodrigues Sampaio, redator principal do jornal $A$ revolução de setembro; a de Pedro Venceslau de Brito Aranha (1886) sobre Mendes Leal Júnior, outro dos jornalistas-políticos oitocentistas portugueses; o jornal especial (número único) dirigido por Alberto Bessa (1899) e dedicado à memória do escritor romântico e jornalista Almeida Garrett; a biografia e colectânea de textos sobre o jornalista Joaquim Martins de Carvalho, elaborada por Carvalho (1924); a biografia do fundador do Diário de notícias, Eduardo Coelho, elaborada por Alfredo da Cunha (1891), e a elegia que vários autores (1904) fizeram ao mesmo jornalista; a obra de Martins (1964) sobre Manuel de Galhegos, primeiro concessionário da edição do primeiro periódico português, a Gazeta "da Restauração", e seu primeiro presumível redator; as biografias do truculento jornalista Padre José Agostinho de Macedo, partidário do Antigo Regime, elaboradas por Mello (1854) e Olavo (1938); os livros dedicados a Reinaldo Ferreira, o famoso "Repórter X", que se distinguiu pelas suas reportagens de pendor sensacionalista (MENDES et al., [19-?]; PORTELA, 1956); as biografias de Emídio Navarro, fundador de um importante jornal do fim do século XIX e princípio do século XX, o Novidades (NORONHA, 1913; VELOSO, 1910-1911); as biografias do autor de Relações seiscentistas Manuel Severim de Faria, elaboradas por Vasconcelos $(1914,1917)$; a biografia do jornalista e político José Luciano de Castro redigida por Pereira (1890); o livro biográfico sobre 
o jornalista Norberto de Araújo (PORTELA, 1953); e as biografias dos jornalistas e políticos do fim de Oitocentos e princípios de Novecentos Mariano de Carvalho, Barbosa Collen, José d'Alpoim e Cunha e Costa, escritas por Rodrigo Veloso (1910-1911).
O Quadro 1 mostra a distribuição por categorias das diversas histórias do jornalismo publicadas em Portugal e inventariadas no âmbito deste estudo.

QUADRO 1 - Distribuição temática dos livros historiográficos do jornalismo publicados em Portugal, por autores portugueses, até 25 de abril de 1974

\begin{tabular}{|c|c|c|}
\hline Categorias & $\mathbf{N}^{\mathrm{o}}$ de livros & $\%$ \\
\hline $\begin{array}{l}\text { História do jornalismo internacional ou estrangeiro (livros sobre a história do } \\
\text { jornalismo em vários países, podendo ou não incluir Portugal) }\end{array}$ & 5 & 6 \\
\hline História do jornalismo português (livros sobre história do jornalismo nacional) & 14 & 15 \\
\hline $\begin{array}{l}\text { História do jornalismo regional e local (livros sobre história do jornalismo em regiões } \\
\text { ou localidades do país) }\end{array}$ & 16 & 18 \\
\hline $\begin{array}{l}\text { História do jornalismo colonial (trabalhos dedicados à historiografia nas ex-colônias } \\
\text { portuguesas da África e da Ásia) }\end{array}$ & 12 & 13 \\
\hline $\begin{array}{l}\text { História de órgãos jornalísticos (obras dedicadas à história de um único órgão } \\
\text { jornalístico ou à análise historicamente contextualizada do seu discurso) }\end{array}$ & 8 & 9 \\
\hline $\begin{array}{l}\text { História do jornalismo especializado (livros dedicados à história das publicações } \\
\text { segmentadas) }\end{array}$ & 5 & 6 \\
\hline $\begin{array}{l}\text { Hemerografias e catálogos (inventários históricos dos meios de comunicação } \\
\text { jornalísticos que existiram no território nacional) }\end{array}$ & 4 & 4 \\
\hline $\begin{array}{l}\text { História das agremiações profissionais dos jornalistas (obras sobre a história de } \\
\text { organizações de jornalistas) }\end{array}$ & 3 & 3 \\
\hline $\begin{array}{l}\text { Biografias (investigações sobre a vida de jornalistas e o contributo específico que os } \\
\text { biografados deram ao jornalismo) }\end{array}$ & 24 & 26 \\
\hline Total & 91 & 100 \\
\hline
\end{tabular}

Pode concluir-se, face aos dados apresentados, que os investigadores portugueses que escreveram livros sobre história do jornalismo antes de 25 de abril de 1974 deram particular atenção a objetos de estudo que lhes estavam próximos e/ ou que lhes eram acessíveis, pelo que preferiram as histórias biográficas (26\% dos livros), as histórias do jornalismo regional e local (18\% dos livros), as do jornalismo colonial (13\% dos livros) e as de determinados órgãos jornalísticos $(9 \%)$. A história do jornalismo nacional em geral constituiu o foco de atenção de apenas 15\% dos livros e a história do jornalismo em geral foi tema de apenas $6 \%$ dos livros, valores que podem traduzir um certo desinteresse acadêmico e profissional autóctone, quer pelo jornalismo internacional, quer mesmo pelo jornalismo nacional em geral. Menos surpreendentes são as percentagens de livros dedicados à historiografia do jornalismo especializado $(6 \%) \mathrm{e}$ das agremiações profissionais dos jornalistas (3\%), temas que interessarão a poucos historiadores e que têm pouca repercussão pública. 


\section{ALFREDO DA CUNHA: o prolixo}

Alfredo da Cunha começou a interessar-se pela história do jornalismo no fim do século XIX, quando apresentou no $\mathrm{V}$ Congresso Internacional da Imprensa, realizado em Lisboa, em 1898, uma comunicação sobre a origem e desenvolvimento do jornalismo nacional, tema que não mais abandonará (CUNHA, 1930, 1941a, c, 1942). Em especial, o autor debruçou-se, nessas obras, sobre o aparecimento do periodismo português, e batalhou para que se considerasse a Gaz̧eta "da Restauração" (16411647), o primeiro jornal português, em detrimento das Relações de Manuel Severim de Faria, o que fez, inclusivamente, adiar para 1941 as comemorações do tricentenário da imprensa jornalística portuguesa, que alguns queriam realizar em 1926 (tricentenário da primeira Relação de Manuel Severim de Faria).

Alfredo da Cunha escreveu, também, uma excelente história do Diário de Notícias (1914) e ainda um importante texto sobre a história das organizações jornalísticas em Portugal, o primeiro devotado a esse tema (CUNHA, 1941b), no qual relembra a conturbada história das associações e sindicatos jornalísticos desde 1880 até 1941 . Nele, o autor discute as divisões no seio da classe jornalística portuguesa do fim de oitocentos e princípios de novecentos (elites literatas x "proletários", incluindo nesses últimos os que queriam aglutinar todos os trabalhadores da imprensa sob um único telhado), bem como as indefinições sobre os conceitos de jornalismo (ramo da literatura, profissão liberal...) e de jornalista ("escritor de jornal", profissional, repórter...). Recorda, ainda, nesse mesmo texto, as tentativas nunca concretizadas de fundação de uma Ordem dos Jornalistas em Portugal.

O livro principal escrito por Alfredo da Cunha é Elementos para a história da imprensa periódica portuguesa 1641-1821, editado em 1941. Com essa obra, Alfredo da Cunha pretendeu dar a conhecer o trajeto da imprensa periódica portuguesa nos séculos XVII, XVIII e XIX (essencialmente até à Revolução Liberal e período subsequente). Trata-se de um livro clássico e minucioso sobre a história do jornalismo em Portugal, no qual foram beber obras posteriores.

Ao contrário de autores anteriores, designadamente de Bessa (1904), Alfredo da Cunha opta por não se pronunciar sobre os fenômenos préjornalísticos, preferindo considerar que o verdadeiro jornalismo apareceu em Portugal com a Gazeta "da
Restauração", em 1641, apesar de também se referir às Relações de Manuel Severim de Faria e a dispositivos pré-jornalísticos anteriores a essas Relações, recordando, por exemplo, a Miscelânea de Garcia de Resende, espécie de reportagem em forma de verso, que poderá ter circulado sob a forma de folha volante.

O autor começa por contextualizar o jornalismo português, equacionando-o em função do grau de liberdade de imprensa de que se beneficiou em cada época. Relembra, desde logo, que uma lei implementada por D. João IV proibiu, em 1642 (poucos meses após o início da publicação da Gazeta "da Restauração"), a circulação de gazetas, o que impediu, na versão do autor, um começo salutar da imprensa periódica portuguesa. Esse juízo de Alfredo da Cunha pode ser lido como uma crítica indirecta à censura exercida pelo regime ditatorial de Salazar. Aliás, Alfredo da Cunha (1941a, p. 8) faz uma observação curiosa quando se refere às contradições do uso da expressão "liberdade de imprensa", afirmando que "o [...] intuito [do uso dessa expressão] não tem sido outro senão restringir ou refrear aquela liberdade".

Para Alfredo da Cunha (1941a, p. 4), o jornalismo tornou-se um "gênero de primeira necessidade", de enorme impacto social. O autor relembra, a propósito, que por causa do impacto social do jornalismo se foram inserindo novos vocábulos na língua, correspondentes a outros tantos novos conceitos, por exemplo: jornalismo e jornalista; repórter; periodismo; periodístico, periodista e periodiqueiro; folhetinista e foliculário; diarista e gazeteiro; jornal, revista; artigo, reportagem, entrevista, crônica etc.

Cunha (1941a, p. 35) explica que a invenção da tipografia gutemberguiana promoveu o conhecimento e foi também o invento por trás da aparição dos jornais, que se propõem satisfazer, com relativa frequência e a intervalos regulares, a curiosidade pública, proporcionando-lhe o conhecimento de "histórias presentes" e "casos que aconteceram".

$\mathrm{O}$ autor lembra que a gênese da imprensa periódica em Portugal ocorreu com a publicação da Gazeta "da Restauração" e do Mercúrio português. Esses foram, na designação de Alfredo da Cunha, os "patriarcas do jornalismo português", que não teve, no século XVII, outros representantes dignos de recordação. De acordo com Cunha (1941a, p. 42), à Gazeta pode atribuir-se o título de primeiro periódico de notícias que se publicou em Portugal, e ao Mercúrio, o título de primeiro periódico político, de redacção literariamente cuidada. De qualquer maneira, fazendo 
o balanço do século XVII jornalístico português, Alfredo da Cunha (1941a, p. 65) é cáustico:

do mesmo modo que a dois livros se não chama biblioteca, nem a dois quadros compete a classificação de museu, as duas folhas seiscentistas não podiam representar o jornalismo como força social, ou sequer deixar entrever o predomínio que ele viria a ter na vida dos povos modernos.

Portanto, para o autor não se pode considerar um grande feito terem existido dois periódicos no século XVII, uma vez que esses não teriam contribuído para a edificação do jornalismo como instituição social nem determinaram a aparição de jornalistas profissionais.

O século XVIII é considerado por Alfredo da Cunha como um período amorfo no que diz respeito à evolução da imprensa periódica portuguesa. Ele recorda que, apesar de alguns periódicos, noticiosos (com especial destaque para a Gazeta de Lisboa, a que dedica muitas páginas) ou literários, enciclopédicos e de ideias, terem sido publicados em Portugal nesses cem anos, o jornalismo teve de enfrentar forte censura, inclusive do marquês de Pombal, apesar desse desconsiderar a imprensa, quer a "insípida" imprensa noticiosa quer a de ideias, nem sequer vendo nelas bons agentes de propaganda (CUNHA, 1941a, p. 103). O autor explica, igualmente, que dos periódicos publicados no século XVIII, nenhum era de carácter político, de combate partidário; nenhum pretendia representar a "opinião pública", uma vez que, de acordo com Alfredo da Cunha, a opinião dominante, que abafava ou sufocava todas as tímidas opiniões divergentes, "era a de quem governava". "Não havia lugar a controvérsias ou comentários sobre a matéria de administração e não havia partidos políticos que se digladiassem pela obtenção do poder, porque este concentrava-se no Rei, segundo as doutrinas que prevaleciam no país" (CUNHA, 1941a, p. 114).

Alfredo da Cunha (1941a, p. 121), antes de começar a descrever a imprensa periódica portuguesa no século XIX, cita Henry Maret, segundo o qual "escrever a história do jornalismo no século XIX seria escrever a história do próprio século". Esse foi, de facto, em conformidade com Alfredo da Cunha, o século onde se denominou, pela primeira vez, o jornalismo como o "quarto poder", uma vez que era a força que desfazia as outras três forças. Jules Claretie (apud CUNHA, 1941 a, p. 121) chamou a esse século o século "dos jornalistas", já que esses teriam conseguido que o público aderisse às suas ideias.

Em Portugal, diz Alfredo da Cunha, só apareceram periódicos de combate político no primeiro quartel do século XIX, devido quer às invasões napoleônicas quer ao influxo das ideias revolucionárias e liberais, em luta com as dos absolutistas.

Fundavam-se umas folhas para defenderem outras para atacarem a separação do Brasil; umas criavam-se para provocarem a convocação das Cortes, outras para a combaterem; umas eram partidárias de D. João VI, outras de Carlota Joaquina, e ainda outras de D. Pedro ou de D. Miguel; umas eram dos jacobinos ou malhados, outras dos apostólicos ou corcundas; e até algumas nasciam principalmente para atacarem as redigidas por inimigos pessoais ou antagonistas políticos [...] (CUNHA, 1941a, p. 122).

Apesar de reconhecer que a pressão do regime absolutista refreou bastante a liberdade de imprensa e o ritmo de fundação de jornais, Alfredo da Cunha (1941a,p. 162) registra, igualmente, o seguinte:

Do que não há dúvida é de que a imprensa de parcialidade ou de facção [em Portugal] nasceu do embate das idéias liberais com as absolutistas, pois, enquanto estas forem as únicas professadas e predominantes, os periódicos não tiveram, para se desenvolverem e robustecerem na ginástica da discussão, o estímulo da polêmica partidária e da controvérsia política.

Alfredo da Cunha refere ainda que, no Portugal do século XIX, raro foi o homem de letras ou homem político que não cultivou o jornalismo combativo e partidário e nele não tentou conquistar renome, quando, pelo contrário, no século anterior, os grandes prosadores, poetas, oradores ou políticos raramente se notabilizaram como jornalistas. Entre todos, embora nem sempre pelos melhores motivos, uma personagem sobressai no panorama das lutas entre os jornais políticos das primeiras décadas do século XIX: o talentoso, mas também turbulento, violento, desenfreado eindecoroso padre José Agostinho de Macedo, redator de diversos periódicos pró-absolutistas, que merece de Alfredo 
da Cunha uma análise de dez páginas (CUNHA, 1941a, p. 141-151).

\section{A GRANDE HISTÓRIA DO JORNALISMO PORTUGUÊS: José Manuel Tengarrinha (1965)}

O livro de José Manuel Tengarrinha (1965) História da imprensa periódica portuguesa, reeditado em 1989, é "apenas" a grande obra de referência de todos os que se propõem estudar o jornalismo português durante a Monarquia. De fato, embora as últimas referências do livro digam respeito à I República e ao Estado Novo, o trabalho mais relevante do autor diz respeito ao período monárquico. Apesar de existirem outras histórias do jornalismo português anteriores ao livro de Tengarrinha, nenhuma atingiu o detalhe nem o nível de interpretação e contextualização do tema evidenciados por esse autor.

O livro de Tengarrinha não é um inventário de jornais, opção que o autor recusa desde o início: "Houve especial preocupação em não cair na enumeração excessivamente longa de periódicos $[\ldots]$, que parece ser [...] característica dominante dos trabalhos até agora efectuados" (TENGARRINHA, 1965, p. 24). Assim, o autor, embora dando sempre as necessárias referências hemerográficas e autorais (mencionando o nome de vários jornalistas e outros intervenientes no processo jornalístico), tentou contextualizar a gênese e desenvolvimento do jornalismo português em função das circunstâncias históricas (culturais, econômicas, tecnológicas etc) de cada época, merecendo-lhe particular atenção os mecanismos de controle da imprensa, nomeadamente a censura e o licenciamento, que, no seu juízo, quando aplicados, retardaram não apenas o desenvolvimento do jornalismo nacional mas também o do próprio país, conforme sucedeu durante o Estado Novo:

Em contraste com a relativa facilidade com que dantes se fundava um jornal, exigem-se agora [Estado Novo] [...] pesados investimentos de capitais, cujos interesses, depois, é necessário defender. Esta circunstância e os obstáculos de ordem legal [...] (entre os quais avultam a censura prévia, as dificuldades na obtenção de alvarás e o rigor no reconhecimento da "idoneidade intelectual e moral dos responsáveis pela publicação") reduzem a liberdade de movimentos da nossa imprensa actual a limites muito estreitos. Vemos, assim, como a compressão ou a libertação da imprensa é determinada por factores profundos, acompanhando a compreensão ou a libertação da actividade humana nas suas diversas manifestações. E vemos, também, como a evolução do jornalismo se enquadra num amplo conjunto de circunstâncias que, por um lado, o determina e sobre o qual, por outro lado, ele age. [...] A história da imprensa portuguesa não poderá ser observada como um fenómeno isolado e sui generis, mas como um dos aspectos [...] da história da nossa cultura (TENGARRINHA, 1965, p. 248).

Tengarrinha divide a história da imprensa portuguesa em três períodos: 1) Os primórdios da imprensa periódica em Portugal (até cerca de 1820); 2) A imprensa romântica ou de opinião $(1820 \mathrm{em}$ diante); 3) A organização industrial da imprensa, marcada pela fundação do Diário de Notícias (1865; 1864, caso se considerem os números experimentais).

Sobre o primeiro período, o autor relembra que, considerando a periodicidade uma das marcas do jornalismo impresso, então a primeira publicação jornalística portuguesa é a Gazeta "da Restauração", que propagandeava a causa independentista portuguesa e tinha um carácter noticioso. Diz que as técnicas jornalísticas eram rudimentares e que os autores escreviam, frequentemente, baseados nas crenças, rumores e boatos e não verificavam as informações. Realça que a censura e o licenciamento constituíram travões ao desenvolvimento do jornalismo português. No entanto, descreve a diversificação do panorama jornalístico nacional graças ao aparecimento de publicações literárias, científicas e de ideias no século XVIII, bem como o aparecimento dos primeiros diários, no fim dessa primeira época. Evoca, também, a imprensa da primeira emigração, que chegou a circular clandestinamente no país, e a imprensa clandestina autóctone, quer durante as invasões francesas, quer durante o período anterior à Revolução Liberal de 1820.

O segundo período identificado por Tengarrinha é o do aparecimento e crescimento da imprensa política, permitida pela Revolução Liberal de 1820, acontecimento que fez disparar o ritmo da publicação de periódicos por todo o Portugal. Classicamente, o autor relembra, porém, os constrangimentos à imprensa durante o período miguelista 
e a emigração liberal, que induziu à publicação de jornais portugueses no estrangeiro. Esses, recorda José Manuel Tengarrinha, entravam e circulavam clandestinamente em Portugal.

A organização do jornal e a situação do jornalista no jornalismo oitocentista também não passam despercebidas a Tengarrinha, que as descreve assim:

um jornal de certa importância era, em geral, constituído por um editor (responsável perante as autoridades), por um redactor-responsável (ou chefe da redacção), por um ou dois noticiaristas encarregados da tradução das folhas estrangeiras e da informação nacional [...] e um folhetinista [...]. Uma secção que toma então grande desenvolvimento é a de "cartas ao redactor", através da qual se estabelece uma comunicação íntima e constante entre o jornal e o leitor. [...] O chefe da redacção era o verdadeiro espírito e a alma da publicação. O jornal, geralmente, era um homem, mais até do que um partido. [...] Sendo o jornal todo, nele se concentravam não apenas as funções de redacção, mas também [...] as de direcção e administração. [...] Além dos elementos da redacção, o jornal contava com colaboradores eventuais, mais ou menos identificados com a linha política do jornal (TENGARRINHA, 1965 , p. 153-154).

Ortodoxamente, Tengarrinha refere, ainda, as restrições à liberdade de imprensa do fim da Monarquia, sem se esquecer de abordar o aparecimento da imprensa ilustrada, o surgimento da imprensa operária e revolucionária, a evolução da tipografia e a introdução das rotativas, os movimentos reivindicativos dos tipógrafos, as formas de distribuição dos jornais nessa altura (por correio, por caminho-de-ferro, por assinaturas e através dos ardinas) e a sua influência na opinião pública. Sobre essa última temática, escreve Tengarrinha (1965, p. 174-177), realçando a ideia de agendamento que já vinha de autores como Gabriel Tarde:

Qual seria, efectivamente, o grau de influência dos jornais na opinião pública? [...] É claro que [...] esse grau de influência varia [...] de época para época, de acordo com as suas condições específicas [...]. Do que não resta dúvida [...] é que foi nesta $2^{a}$ época [final da Monarquia] que o jornalismo exerceu mais vincada influência na opinião pública. $\mathrm{O}$ âmbito dos leitores alargou-se [...] até à pequena burguesia. [...] Os jornais [...] eram [...] o centro da vida política e social. Por eles se liam os debates nas câmaras, se conheciam as disposições oficiais, se discutiam as directrizes do partido ou da facção expressas nos artigos de fundo, se sabiam os principais acontecimentos [...], se adquiriam conhecimentos [...], se dispunha de um meio de distracção e divertimento. Essa influência é tanto mais evidente quanto é certo que os leitores se agrupavam em torno dos jornais com que se identificavam [...], sendo de admitir [...] que as opiniões expostas [...] fossem reforçar ou corrigir as suas ideias. [...] Mas neste ponto da questão não podemos esquecer a esclarecida afirmação de R. Manevy: "A imprensa faz a opinião [...] na medida em que esta se quer deixar fazer" [...].

O autor evoca, igualmente, ao longo das páginas dedicadas ao segundo período do jornalismo português, os grandes nomes de políticos e escritores que se viam a si mesmos como jornalistas e que colaboraram, como folhetinistas e redatores (articulistas), nessa que Tengarrinha denomina de "imprensa romântica".

O terceiro período, de industrialização da imprensa, de acordo com Tengarrinha, fez esmorecer a imprensa opinativa e promove a imprensa informativa, o noticiário, a reportagem e, consequentemente, a figura do repórter.

Esta preferência que o público mais largo manifesta pela informação objectiva (e não pela opinião), e até pelo pendor sensacionalista que a informação começa a tomar, só pode compreender-se por uma nova atitude mental da pequena e média burguesia [...] especialmente permeável aos relatos de aventuras ou de histórias de amor, como que buscando uma fuga emocional à estreita rotina do dia a dia. [...] Na necessidade de encontrar um público mais largo, o jornal procura manter uma atitude imparcialmente objectiva, dirigindo-se assim a todos [...] os que sabem ler, cujo número vai crescendo gradualmente. Embora sem esquecer a camada mais instruída, que forma [...] o grosso dos assinantes, 
dirige-se assim ao novo público, menos abastado e instruído, com gostos menos exigentes e requintados (TENGARRINHA, 1965, p. 194).

Que influência passa, então, o jornal informativo a exercer sobre o público nesse terceiro período da imprensa periódica portuguesa? José Manuel Tengarrinha (1965, p. 194-196) tenta responder à questão, embora numa perspectiva extremamente negativa:

não distribuindo senão uma informação fragmentária, superficial e sem continuidade, a imprensa [...] noticiosa, se é certo que pode esclarecer o leitor acerca de determinado acontecimento, não o ajuda a formar uma posição crítica em face dele. Atendo-se a dados meramente objectivos, não se identifica com o pensamento do leitor nem pretende, pelo menos aparentemente, exercer qualquer influência sobre ele. [...] O jornal agora [...] tem de procurar o público, descer ao seu nível, adivinhar-lhe os gostos e apetites [...], ir ao encontro da sua mentalidade. Perde assim completamente o seu valor formativo. Com efeito, na medida em que os jornais deixavam de apoiar-se em facções políticas para serem mantidos por grupos financeiros, a imprensa transformou-se numa indústria [...]. O jornal passa a ser [...] uma mercadoria [...], apenas com valor durante algumas horas.

A transformação industrial da imprensa, recorda Tengarrinha, trouxe modificações nas redações. Por um lado, a chefia de redação passa a ter mais funções de coordenação e supervisão do que de redação. O secretário de redação torna-se fulcral para a organização diária do trabalho, numa redação que comporta dezenas de jornalistas. $\mathrm{O}$ novo jornalista assalariado da imprensa industrial pode até não se identificar com o que escreve, mas, segundo Tengarrinha (1965, p. 208), tem de o escrever, pois:

é apenas o operário de uma mercadoria que é necessário vender o mais possível e com a qual não está ligado nem pelas ideias nem pelos interesses, pois não participa nos lucros e recebe um salário fixo que lhe permite viver exclusivamente dessa actividade.
Apesar de tudo, e tal e qual como surgiram jornais noticiosos em plena época de domínio da imprensa partidária, no fim da Monarquia, num período de crescente domínio da imprensa informativa, apareceu, diz Tengarrinha (1965, p. 211), uma imprensa combativa revolucionária, de cariz republicano, por um lado, ou de aparência anarquista ou socialista, por outro. Por isso, multiplicaramse as tentativas de controle da imprensa durante esse terceiro período da história do jornalismo em Portugal.

\section{CONCLUSÕES} o seguinte:

Os dados apresentados permitem concluir

1) Os autores portugueses começaram a olhar para a história do jornalismo, nas suas diversas dimensões, no século XIX. Nesse particular, Portugal acompanhou as tendências acadêmicas que se desenhavam no estrangeiro, não apenas devido a um efeito de contágio permitido pelas interações académicas, jornalísticas (relembre-se o papel dos congressos internacionais da imprensa) e culturais, mas também porque os autores portugueses, ao observarem quer o processo de industrialização da imprensa, quer o papel político dos jornais, consciencializaram-se da crescente importância do jornalismo no mundo. No entanto, a concepção da imprensa como instituição social proposta pelas ciências sociais emergentes no século XIX só se insinuará em Portugal já no século XX, sendo observável, por exemplo, na obra Elementos para a história da imprensa periódica portuguesa, de Alfredo da Cunha (1941).

2) As ideias revisionistas no que respeita à concepção e à construção da História também só chegaram a Portugal no século XX, reflectindo-se, então, em várias obras emblemáticas. As concepções da História positivista ou 
metodológica, de que são exemplos as histórias hemerográficas e biográficas do jornalismo e de jornalistas portugueses elaboradas ao longo de todo o período estudado, começaram, então, a ser contaminadas por outras correntes teóricas, primeiro por alguns aspectos do revisionismo marxista (principalmente no que se refere à inscrição dos factos históricos no âmbito de um sistema configurado pelas relações de produção preconizadas pelo materialismo histórico) e, mais tarde, pela Nova História (sobretudo no que se refere à concepção complexa da história e ao cruzamento de variáveis de natureza variada - econômica, política, social, cultural, das ideias e mentalidades - para explicar os fatos históricos, vistos mais como possibilidades e hipóteses do que como verdadeiros fatos). Fundamentam essa conclusão a publicação de obras como: Umjornalna revolução: "O mundo" de 5 de Outubro de 1910 (BAPTISTA, 1966); História da imprensa periódica portuguesa (TENGARRINHA, 1965); Imprensa operária no portugal oitocentista (1825-1905) (OLIVEIRA, 1973); e em menor grau, Elementospara a história da imprensa periódica portuguesa (CUNHA, 1941).

3) Finalmente, deve sublinhar-se que os primeiros historiadores portugueses do jornalismo deram particular atenção a objetos de estudo que lhes estavam próximos e/ou que lhes eram acessíveis, sendo de destacar as biografias, as histórias do jornalismo regional, local e colonial, as histórias de determinados órgãos de comunicação social e as histórias do jornalismo nacional. Foram poucos os livros publicados sobre história do jornalismo em geral, talvez por causa da inexistência de cursos superiores de Jornalismo e de centros de pesquisa sobre Jornalismo em Portugal durante o período estudado.

\section{REFERÊNCIAS}

ANDREWS, A. History of British journalism. London: Richard Bentley, 1859.

ARAGÃO, M. A imprensa no Distrito de Viseu: fragmento histórico. Viseu: Tipografia Popular d'A Liberdade, 1900.

BAPTISTA, J. Um jornal na revolução: “o mundo" de 5 de outubro de 1910. Lisboa: Seara Nova, 1966.

BASTO, A. M. Três fases do jornalismo portuense. Porto: Câmara Municipal do Porto, 1940.

BERNHEIM, E. Lehrbuch der historischen methode und der geschichtsphilosophie. München: Duncker \& Humblot, 1908.

BESSA, A. (Dir.). Garrett: número único em homenagem à memória do insigne reformador da literatura, do teatro e do jornalismo português. Lisboa: Imprensa Lucas e Associação da Imprensa Portuguesa, 1899.

O jornalismo: esboço histórico da sua origem e desenvolvimento até aos nossos dias. Lisboa: Viúva Tavares de Castro, 1904.

100 Anos de vida: a expansão da imprensa brasileira no primeiro século da sua existência. Lisboa: Gomes de Carvalho, 1929.

BLEYERS, W. Main currents in the history of American journalism. Boston: Houghton Mifflin, 1927.

BOAVIDA PORTUGAL, J. M. Para a história da casa da imprensa. Lisboa: Oficinas Gráficas da Gazeta dos Caminhos de Ferro, 1959.

BOURNE, H. R. F. English newspapers: chapters in the history of journalism. [S.1.]: Chatto \& Windus, 1887.

BRANCO, Capitão J. V. Subsídios para a história da imprensa Algarvia de 1833 aos nossos dias. Faro: Tipografia Caetano, 1938.

BRITO ARANHA, P. V. Subsídios para a história do jornalismo nas províncias ultramarinas portuguesas. Lisboa: Imprensa Nacional, 1885.

Mendes Leal Júnior: memórias várias políticas, literárias e bibliográficas. Lisboa: Diário de Notícias, 1886.

CARQUeJA, B. O comércio do Porto ao completar setenta anos: notas para a sua história. Porto: O Comércio do Porto, 1924. 
O comércio do Porto ao completar oitenta anos: notas para a sua história. Porto: O Comércio do Porto, 1934.

CARVALHO, A. J. T. Notas para a história do jornalismo em elvas. Elvas: Tipografia Progresso, 1931.

CARVALHO, A. M. Joaquim Martins de Carvalho: apontamentos biográficos. Coimbra: Imprensa Académica, 1924.

CASTRO, J. L. Catálogo do jornalismo português, antigo e moderno, ou publicações periódicas, políticas, científicas, literárias, religiosas, etc. Lisboa: Livraria de João Pereira da Silva \& Filhos, 1897.

CERQUEIRA, E. O centenário do "Campeão do Vouga": notas de recordação do primeiro Jornal aveirense. Aveiro: Arquivo do Distrito de Aveiro, 1952.

CODAM. Contribuição para a história da imprensa em Moçambique. Lourenço Marques: Codam SARL, 1973.

COELHO, E. Notice Présentée. In: CONGRES LITTERAIRE INTERNATIONAL DE LISBONNE, AVEC FAC-SIMILE DE LA PREMIERE GAZETTE PUBLIEEEN PORTUGAL, OFFERT AU CONGRES LITTERAIRE INTERNATIONAL DE LISBONNE, 1., 1881, Lisboa. Annales... Lisboa: [s.n.], 1881.

Le Portugal et Gutenberg: quelques indications agregees sur le develloppement de la presse Portugaise Offertes Aux Membres. In: CONGRES INTERNATIONAL DE LA PRESSE, 5., 1898. Lisboa. Annales... Lisboa: Tipografia do Comércio, 1898.

COSTA, A. Breve história da imprensa cinematográfica em Portugal. Porto: Cine-club do Porto, 1954.

COSTA, F. A. A. C. No primeiro centenário da introdução do jornalismo e da imprensa em Vila Franca do Campo. Ponta Delgada: Tipografia Diário dos Açores, 1963.

CUNHA, A. Eduardo Coelho: a sua vida e a sua obra. Alguns factos para a história do jornalismo. Lisboa: Tipografia Universal, 1891.

La presse périodique en Portugal: bref mémoire présenté. In: CONGRES INTERNATIONAL DE LA PRESSE, A LISBONNE, 5., 1898, Lisboa. Annales... Lisboa: Diário de Notícias, 1898.

O Diário de notícias: a sua fundação e os seus fundadores. Lisboa: Tipografia Universal, 1914.
CUNHA, A. M. O tricentenário da publicação do primeiro periódico português: as relações de Manuel Severim de Faria e as Gazetas da Restauração. Coimbra: Imprensa da Universidade, 1930.

Olisipo, berço do periodismo português: o tricentenário da "Gazeta" Cognominada "da Restauração". Lisboa: Amigode Lisboa, 1939.

Elementos para a história da imprensa periódica portuguesa (1641-1821). Lisboa: Academia das Ciências de Lisboa, 1941a.

Jornalismo nacional: das malogradas associações de imprensa à alvitrada ordem dos jornalistas portugueses. Lisboa: Tipografia Gráfica Santelmo, 1941b.

Relances sobre os três séculos de jornalismo português. Lisboa: Gráfica Santelmo, 1941c.

Periódicos e relações, periodistas e noticiários. Lisboa: Academia das Ciências de Lisboa, 1942.

CUNHA, J. G. Jornalismo do distrito de Castelo Branco. Fundão: Tipografia da Beira Baixa, 1893.

DEL ARCO, L.; MUÑOZ, C. La prensa periódica en España durante la Guerra de la Independencia. Castellón: Tipografia Joaquín Barberá, 1914.

DIAS, R. N.; EÇA, F. G. A. A imprensa periódica em Moçambique (1854-1954). Lourenço Marques: Imprensa Nacional de Moçambique, 1957.

FERNANDES, J. G. O jornalismo em Macau. Lisboa: Sociedade de Geografia de Lisboa, 1888.

FREIRE, J. P. O Diário de Notícias: da sua fundação às suas bodas de diamante. Escôrco da sua história e das suas efemérides. Lisboa: Diário de Notícias, 1939.

FREITAS, J. A. Resenha cronológica do jornalismo Madeirense. Funchal: Empresa do Diário de Notícias do Funchal, 1908.

GALRÃO, C. Concelho de Mafra: Imprensa Regional. Mafra: Tipografia Liberty, 1937.

GAMA, E. Jornalismo campomaiorense. Coimbra: Coimbra Editora, 1956.

GOMES, L. F. Os jornalistas do Porto e a sua associação. Porto: Associação de Jornalistas e Homens de Letras do Porto, 1925.

GONÇALVES,J.J.A informação em Angola: elementos para o seu estudo. Lisboa: ISCSPU, 1964. 
A informação em Moçambique: contribuição para o seu estudo. Lisboa: Companhia Nacional Editora, 1965.

A informação na Guiné, em Cabo Verde e em São Tomé e Príncipe. Lisboa: ISCSPU, 1966.

A informação nas províncias do oriente: elementos para o seu estudo. Lisboa: Universidade Técnica de Lisboa/ISCSPU, 1966-1967.

Alguns aspectos e problemas da evolução e condicionamento da imprensa em Portugal. Lisboa: Academia Internacional da Cultura Portuguesa, 1972.

GRACIAS,J.A. I.Aimprensa em Goa nos Séculos XVI, XVII e XVIII: apontamentos histórico-bibliográficos. Nova Goa: Imprensa Nacional, 1880.

GRAVE, J. M. A imprensa no distrito de Castelo Branco. Famalicão: Tipografia Minerva, 1929.

HATIN, E. Bibliographie historique et critique de la presse periodique Française, precede d'un essai historique et statistique sur la naissance et le progres de la presse periodique dans les Deux Mondes. Paris: Firmon-Didot, 1866.

HATIN, E. Histoire politique et litteraire de la presse en France. Paris: Pulet-Malassis \& de Broise, 1859-1864. $8 \mathrm{v}$.

HUDSON, F. Journalism in the United States, from 1690 to 1872. New York: Harper, 1873.

JESUS, F. H. Subsídios para a história do jornalismo Setubalense. Setúbal: Câmara Municipalde Setúbal, 1955.

KOBRE, S. The development of the colonial newspaper. Pittsburgh: Colonial Press, 1944.

LACERDA, A. A irradiação do pensamento. Porto: O Comércio do Porto, 1904.

LAPA, A. S. A palavra Lisboa na história do jornalismo português. Lisboa: Tipografia Editorial Império, 1956.

LE CLERC, J. V. Les journaux Chez les Romains. Paris: Firmin Didot, 1838.

LEAL, S. C. da S. Jornais Indo-Portugueses. Lisboa, Imprensa de Libano da Silva, 1898.

LEE, J. M. History of American journalism. Boston: Houghton Mifflin, 1917.

MACIEL, A. Viagem de cem anos. Viana do Castelo: Câmara Municipal de Viana do Castelo, 1958.
MARTA, C. Jornalismo Figueirense. Figueira da Foz: Tipografia Popular, 1921.

MARTINS, H. Manuel de Galhegos: um poeta entre a monarquia dual e a restauração. Anadia: Tipografia Cisial, 1964.

MARTINS, R. Pequena história da imprensa portuguesa. Lisboa: Editorial Inquérito, 1942.

MELLO, J. L. C. Biografia do Padre José Agostinho de Macedo. Porto: Tipografia Francisco Pereira d'Azevedo, 1854.

MENDES, A. et al. O livro do repórter X. Lisboa: Agência Editorial Brasileira, [19--?].

MONTE, G. O Jornalismo Eborense 1846-1954. Évora: [s.n.], 1955.

MORAIS, C. A. Lourenço de Anvers, primeiro impressor da "Gazeta" Cognominada da Restauração. Lisboa: Tipografia Empresa do Anuário Comercial, 1941.

MORAIS, T. Comemoração do tricentenário do $1^{\circ}$ periódico português “Gazeta de 1641”. Lisboa: [s.n.], 1941.

MORISON, S. The english newspaper. Cambridge: Cambridge University Press, 1932.

MOTT, F. L. American journalism: a history of newspapers in the United States Through 250 Years 1690 to 1940. New York: Macmillan, 1962. (Publicado originalmente em 1941/1942).

NORONHA, E. Vinte e cinco anos nos bastidores da política. Emídio Navarro e as "Novidades". A sua vida e sua obra política e jornalística. Porto: Companhia Portuguesa Editora, 1913.

NORONHA, T. Ensaios sobre a história da imprensa. Lisboa: Tipografia Franco-Portuguesa de Lallemant \& Ca, 1857.

NUNES, J. A. Jornais, homens e factos de portimão. Lisboa: Casa do Algarve, 1962.

OLAVO, C.A Vida turbulenta do Padre José Agostinho de Macedo. Lisboa: Livraria Editora Guimarães, 1938.

OLIVEIRA, A. L. Jornais e jornalistas madeirenses. Braga: Editorial Pax, 1969.

OLIVEIRA, C. Imprensa operária no Portugal oitocentista (1825-1905). Lisboa: [s.n.], 1973.

OLIVEIRA, L. C. Imprensa clandestina em Coimbra: apontamento histórico. Lisboa: Gráfica Boa Nova, 1958. 
PACHECO, Ó. Pequena história de um grande jornal. Lisboa: Diário de Notícias, 1964.

PARK, R. E. The natural history of the newspaper. American Journal of Sociology, v. 29, n. 3, p. 273289, 1923.

PEREIRA, A. X. S. O jornalismo português. Lisboa: Tipografia Soares, 1895.

Os jornais portugueses. Lisboa: Imprensa de Libano da Silva, 1897.

PEREIRA, E. Traços biográficos, políticos e jornalísticos do Ex.mo senhor conselheiro José Luciano de Castro. Lisboa: [s.n.], 1890.

PINA, L. Isagoje histórica do jornalismo médico. Porto: Costa Carregal, 1945.

PINTO, J. L. et al. António Rodrigues Sampaio: homenagem prestada à sua memória pela Imprensa do Porto. Porto: Real Tipografia Lusitana, 1882.

PORTELA, A. Norberto de Araújo: o jornalista e o escritor. Lisboa: Gazeta dos Caminhos-de-Ferro, 1953.

Reinaldo Ferreira (Repórter X): memórias de um ex-morfinómamo. Lisboa: Tipografia Companhia Nacional Editora, 1956.

PRUTZ,R.E.Geschichte desDeutschenJournalismus. Göttingen: Vandernhoeck \& Ruprecht, 1971. (Publicado originalmente em 1845).

ROSADO, N. A imprensa. Lisboa: Ministério da Educação Nacional, 1966.

ROSS, I. Ladies of the press. New York: Harper, 1936.

SALGADO, J. Virtudes e malefícios da imprensa: escorço histórico sobre a origem, evolução e ética do jornalismo. Porto: Portucalense Editora, 1945.

SILVA LEAL, S. C. Jornais Indo-Portugueses. Lisboa: Imprensa de Libano da Silva, 1898.

SILVA, A. A. C. C. Subsídios para a história da imprensa farmacêutica portuguesa. Coimbra: Faculdade de Farmácia da Universidade de Coimbra, 1974.
SILVA, J. P. Catálogo do jornalismo português antigo e moderno ou publicações periódicas, científicas, literárias, religiosas, etc. Lisboa: Livraria de João Pereira da Silva, 1892.

SOLOMON, L. Geschichte des Deutschen Zeitungswesens. Leipzig: Bd. I. Oldenburg, 1900-1906.

STUTTERHEIM, K. von. The press in England. London: George Allen and Unwin, 1934.

TEIXEIRA, L. O Diário de Notícias e o século XIX. Lisboa: Grupo Amigos de Lisboa, 1940.

TEIXEIRA. M. A imprensa periódica portuguesa no extremo-oriente. Macau: Notícias de Macau, 1965. v. 22.

TENGARRINHA, J. História da imprensa periódica portuguesa. Lisboa: Portugália, 1965.

VÁRIOS AUTORES. Eduardo Coelho. Coimbra: Minerva Central, 1904. (Homenagem de um grupo de conimbricenses à memória do fundador do Diário de Notícias).

VASCONCELOS, J. L. Severim de Faria: notas biográfico-literárias. Coimbra: Imprensa da Universidade, 1914.

Severim de Faria: $2^{\mathrm{a}}$ memória. Coimbra: Imprensa da Universidade, 1917.

VELOSO, R. Jornalistas portugueses. Famalicão: Tipografia Minerva, 1910-1911. 6 v.

Recebido: 20/10/2009

Received: 10/20/2009

Aprovado: 25/10/2009

Approved: 10/25/2009

Revisado: 18/12/2009

Reviewed: 12/18/2009 